\title{
Comparison of Nasal and Frontal BIS Monitoring in Neurosurgery. Does Site of Sensor Placement Effect BIS Values?
}

Hajiyeva K. *, Meco B.C. *, Ozgural O.**, Yildirim Guclu C.*, Yorukoglu D*.

*Ankara University School of Medicine, Dept of Anaesthesiology \& Intensive Care, Ankara, Turkey

** Ankara University School of Medicine, Dept of Neurosurgery, Ankara, Turkey

Intraoperative awareness is a serious but preventable complication of general anaesthesia (I). Bispectral index (BIS) is the most widely used method to monitor anaesthesia depth. BIS monitoring require attachment of forehead sensors, posing a challenge when the surgical field involves the forehead.

Material and Methods: We aimed to compare the gold standard forehead position of BIS sensors with an alternative position across the nasal dorsum for neurosurgical procedures. Additionally, assuming that local surgical manipulation might affect BIS values in cranial cases, caseload was divided equally between cranial and vertebral procedures to be assessed.

After ethical committee approval and informed consent, 62 ASA I-III adult patients scheduled for elective neurosurgical operations were enrolled in this prospective observational study. In all patients both frontal and nasal BIS sensors were placed before anesthesia induction. Total intravenous anaesthesia with propofol and remifentanil were used and guided by frontal BIS for depth of anesthesia in all. Frontal and nasal BIS scores were recorded before induction and repeated at 15 minutes intervals after intubation, during the intraoperative period and emergence.
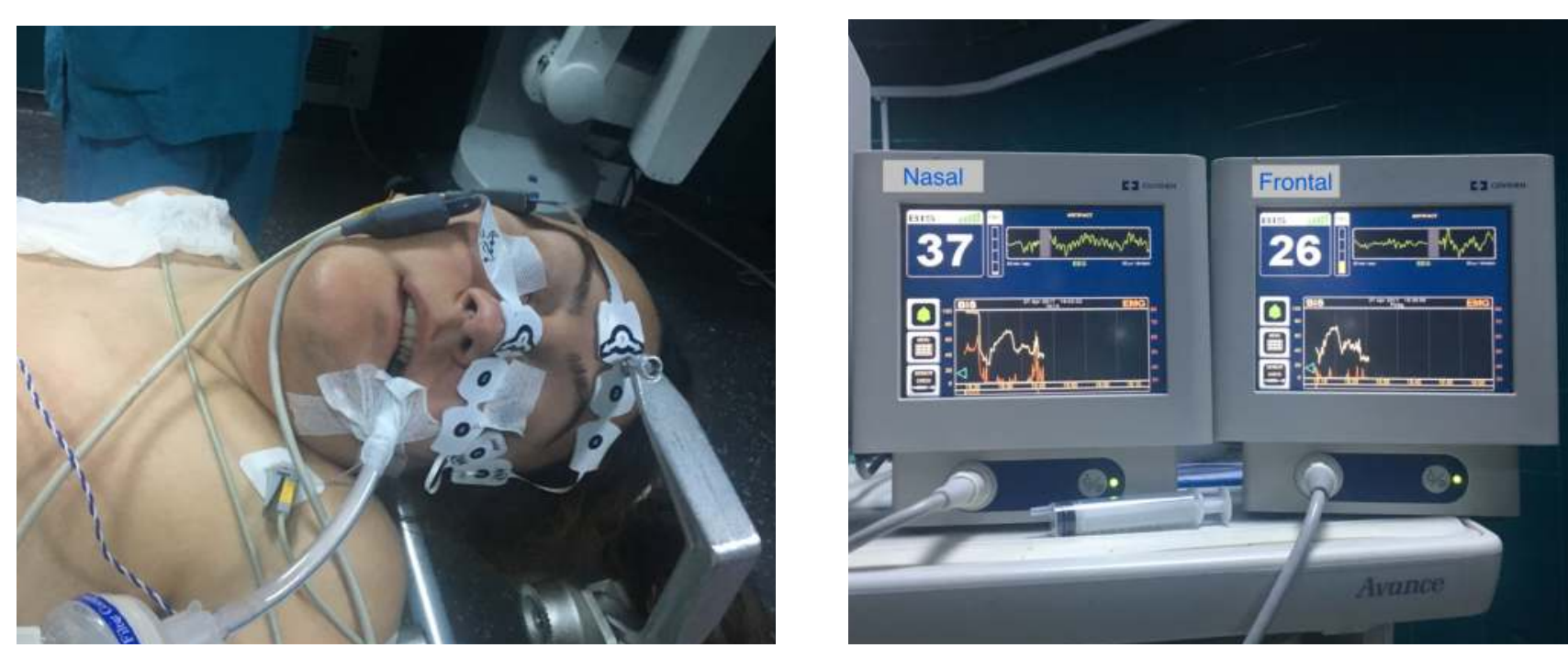

Frontal and nasal BIS values were compared in all, but also separately according to the site of surgery in cranial ( $n: 3 \mathrm{I})$ versus vertebral (n:3I) cases.

Collected data were analyzed with the SPSS for Windows version 15.0. Descriptive statistics were given as mean \pm SD.Interclass correlation coefficients (ICC) were calculated.

Figure I. Nasal and fronatal BIS sensor placement

Results and Discussion: Patients' characteristics are presented in table I. The mean BIS value during the surgery from frontal versus nasal sensors were $49 \pm 22$ and $49 \pm 21$ respectively ( $\mathrm{n}: 62)$. These values were statistically correlated (ICC 0.78, $\mathrm{p}<0.00 \mathrm{I}$ ) indicating that nasal BIS measurement does not reveal a disadvantage for routine use when needed.

Table 1 Patient Demographics

\begin{tabular}{|l|l|}
\hline Age $(\mathrm{yr})$ & $46.25 \pm 15.36$ \\
\hline Gender $(\mathrm{F} / \mathrm{M})$ & $28 / 34$ \\
\hline ASA I-II & $29 / 33$ \\
\hline Height $(\mathrm{cm})$ & $165.49 \pm 8.17$ \\
\hline Weight $(\mathrm{kg})$ & $64.80 \pm 1 \mathrm{I} .53$ \\
\hline BMi $\left(\mathrm{kg} / \mathrm{m}^{2}\right)$ & $23.49 \pm 3.05$ \\
\hline Operation $(\mathrm{n}: 62)$ & Spinal (3I) and cranial (3I) \\
\hline
\end{tabular}

100

$$
\text { " }
$$

